\title{
STRATEGI PENGEMBANGAN RISET DALAM BIDANG IPTEK NUKLIR DALAM RANGKA PENYIAPAN SDM YANG BERKUALIFIKASI TINGGI
}

\author{
ZAKI SU’UD \\ Jurusan Fisika Institut Teknologi Bandung, \\ Jl. Ganesha 10, Bandung 40132, Telp.022-253-4094, Fax 022-250-6452 \\ E-mail : szaki@fi.itb.ac.id
}

\begin{abstract}
Abstrak
STRATEGI PENGEMBANGAN RISET DALAM BIDANG IPTEK NUKLIR DALAM RANGKA PENYIAPAN SDM YANG BERKUALIFIKASI TINGGI. Iptek Nuklir memiliki aplikasi yang luas baik dalam bidang energi, kedokteran/kesehatan, industri, pertanian, keamanan, militer dsb. Secara umum Iptek nuklir merupakan Iptek berkadar tinggi dan memerlukan prasarat tertentu dan regulasi tertentu untuk mengimplementasikannya dengan baik. Reaktor Nuklir untuk pembangkitan energi listrik (PLTN), desalinasi air laut, persuplai panas bagi proses kimia dan revitalisasi sumursumur minyak habis pakai telah mengalami evolusi dari waktu ke waktu. Pasca kecelakaan Chernobyl maka terjadi pergeseran paradigma secara mendasar pada disain dan keselamatan reaktor daya Nuklir dan saat ini perkembangan terbaru dalam disain reaktor daya Nuklir dikenal sebagai generasi IV PLTN. Pelibatan mahasiswa dalam kegiatan riset merupakan salah satu strategi yang dapat ditempuh untuk menciptakan SDM handal dan berkualitas dalam bidang Nuklir khususnya yang menuntut kemampuan analisis yang cukup tinggi baik dalam bidang perancangan netronik, perancangan termal hidrolik dan analisis keselamatan reaktor. Berdasarkan pengalaman yang telah cukup lama (10 tahun lebih) mahasiswa S1 - S2 maupun S3 dapat mengikuti kegiatan riset dalam bidang reaktor Nuklir asalkan sebelumnya ditunjang dengan perkuliahan dan praktikum yang memadai sehingga mereka memiliki kesiapan yang baik.
\end{abstract}

Kata kunci: Iptek nuklir, penyiapan SDM

\section{PENDAHULUAN}

Untuk menjamin pertumbuhan ekonomi yang berkelanjutan yang sekaligus dapat mengurangi dampak buruk pada lingkungan, kontribusi energi nuklir terhadap suplai energi di dunia harus ditingkatkan dan disebar ke negara-negara yang belum memanfaatkan energi nuklir. Saat ini 63\% energi listrik dihasilkan oleh bahan bakar fosil yang sarat dengan gas rumah kaca (green house gases) dan polutan lainnya.

Di sisi lain cadangan energi listrik nasional cukup kritis khususnya untuk berbagai daerah di luar Jawa. Mengingat bahwa kebutuhan tiap provinsi di luar 
Jawa tak terlalu besar (umumnya < 100MWe), sedangkan jaringan distribusi global belum ada maka reaktor moduler berukuran kecil akan menjadi solusi yang tepat. Sebagai gambaran tabel 1 dan 2 menunjukkan situasi cadangan energi listrik kita.

Tabel 1. Beberapa Daerah Kritis Listrik

\begin{tabular}{lllll}
\hline No. & Area/Province & Capacity & Peak Load & Deficit \\
\hline 1. & Aceh & 31 & 46 & -15 \\
2. & West Sumatra and Riau & 210 & 234 & -24 \\
3. & South part of Sumatra & 654 & 665 & -11 \\
4. & Bangka Belitung Island & 19 & 23 & -4 \\
5. & West Kalimantan & 30 & 36 & -6 \\
6. & East Kalimantan & 150 & 165 & -15 \\
7. & South \& Central Kalimantan & 161 & 204 & -43 \\
\hline
\end{tabular}

Source : Indonesian Electricity Company (Pln) Web Site, June 10, 2003

Tabel 2 : Pertumbuhan Konsumsi Listrik di Indonesia

\begin{tabular}{lllllll}
\hline Description & 2001 & 2002 & 2003 & 2004 & 2005 & 2006 \\
\hline Jawa-Bali & & & & & & \\
-Energy Sales (TWh) & 69,12 & 74,82 & 81,74 & 89,27 & 97,47 & 106,22 \\
-Growth Rate (\%) & 11,5 & 6,5 & 6,7 & 7,0 & 7,3 & 7,2 \\
-Peak Demand (GW) & 13,326 & 14,174 & 14,862 & 15,844 & 16,965 & 18,168 \\
-No.Of Customers (Mio) & 20,12 & 20,78 & 21,74 & 22,80 & 23,95 & 25,16 \\
Outer Island & & & & & & \\
-Energy Sales (TWh) & 16,41 & 17,63 & 19,39 & 21,41 & 23,72 & 26,28 \\
-Growth Rate (\%) & 7,3 & 7,4 & 10,0 & 10,4 & 10,8 & 10,8 \\
-Peak Demand (GW) & 3,85 & 4,12 & 4,52 & 4,98 & 5,50 & 6,07 \\
-No.Of Customers (Mio) & 9,48 & 9,95 & 10,69 & 11,50 & 12,38 & 13,32 \\
\hline
\end{tabular}

Source : Indonesian Electric Company (PLN) web site, June 10, 2003

Kecelakaan TMI II dan Chernobyl telah mendorong pergeseran paradigma keselamatan reaktor nuklir ke arah keselamatan inheren/pasif. Berbagai jenis reaktor Nuklir yang dikembangkan pasca kecelakaan Chernobyl memiliki kemampuan keselamatan inheren ini misalnya reaktor berpendingin logam cair (Pb-Bi cair atau sodium cair) (LMFBR), reaktor gas bertemperatur tinggi (HTGR), reaktor air dengan disain khusus, dsb.

Pada reaktor daya generasi IV maka ada 4 kriteria yang harus dipenuhi :

1. Kemampuan keselamatan inheren (aspek keselamatan yang tak terganggu dengan kemungkinan human error, sabotase, kerusakan peralatan pengontrol, dan lain-lain),

2. Mampu mengatasi persoalan limbah nuklir yang dihasilkannya/membakar limbahnya sendiri, 
3. Ekonomis: dengan biaya produksi yang lebih rendah dari PLTN generasi III (untuk generasi III, biaya produksi sekitar 3.5 sen US \$ per kwh) (beberapa disain mengejar target di bawah 2 sen US\$ per kwh),

4. Karakteristik non proliferasi : yaitu disain yang sulit disalahgunakan untuk kepentingan militer.

\section{TINJAUAN UMUM PENGEMBANGAN SDM DENGAN KEGIATAN RISET}

PLTN dan bidang-bidang aplikasi Iptek Nuklir lainnya memerlukan SDM yang handal dan berkualitas tinggi agar dapat menjamin keunggulan aplikasi Iptek Nuklir tersebut serta meminimalisir kemungkinan dampak-dampak negatif yang timbul. Tingkat kualifikasi SDM yang diperlukan memiliki spektrum yang lebar sehingga untuk memenuhi kebutuhan SDM yang ada dapat menggunakan berbagai metode seperti pelatihan (khususnya untuk operator, teknisi umum, dan lain-lain), magang (untuk SDM yang berkualifikasi umum baik namun perlu lebih mendalami masalah lain secara lebih spesifik), serta pelibatan dalam riset (untuk SDM yang dituntut memiliki kualifikasi perancangan, modifikasi, menguji disain dan keselamatan suatu PLTN tertentu, irradiator gamma, akselerator, dsb.), dsb.

Perguruan tinggi memiliki potensi yang besar untuk berperan dalam pengembangan SDM ini dan di sini akan ditinjau studi kasus di KK Fisika Nuklir dan Biofisika ITB. Secara umum kegiatan riset di KK Fisika Nuklir dan Biofisika ITB menyangkut tentang reaktor generasi IV ini serta beberapa reaktor untuk penggunaan khusus seperti reaktor yang dapat dioperasikan di atas kapal, reaktor untuk daerah terpencil, reaktor yang tak memerlukan unit pengaya uranium, dan lain-lain. Selain itu juga dilakukan riset tentang sistem penanganan/pembakaran limbah Nuklir, serta juga tentang perkembangan riset-riset dasar terkait seperti pengembangan sistem simulasi untuk reaktor Nuklir, untuk menghasilkan data Nuklir, dsb

Dalam prakteknya mahasiswa terlebih dahulu diberikan bekal pengetahuan yang diperlukan sebelum melakukan riset melalui perkuliahan, praktikum, serta studi indipenden. Setelah itu mahasiswa mulai masuk ke kegiatan riset secara intensif dibawah bimbingan dosen tugas akhirnya. Kegiatan riset ini memiliki tujuan umum seperti pembiasaan metodologi-metodologi standar yang lazim digunakan para ilmuwan dalam bidang reaktor Nuklir ataupun aplikasi Iptek Nuklir terkait, menemukan hal baru yang merupakan kontribusi bernilai bagi Iptek Nuklir terkait, serta memenuhi standar minimal kualifikasi SDM dalam bidang Iptek Nuklir tertentu.

Gambar 1 menunjukkan evolusi teknologi reaktor daya nuklir (PLTN) di dunia, dimulai sejak generasi I hingga generasi IV. 
The Evolution of Nuclear Power

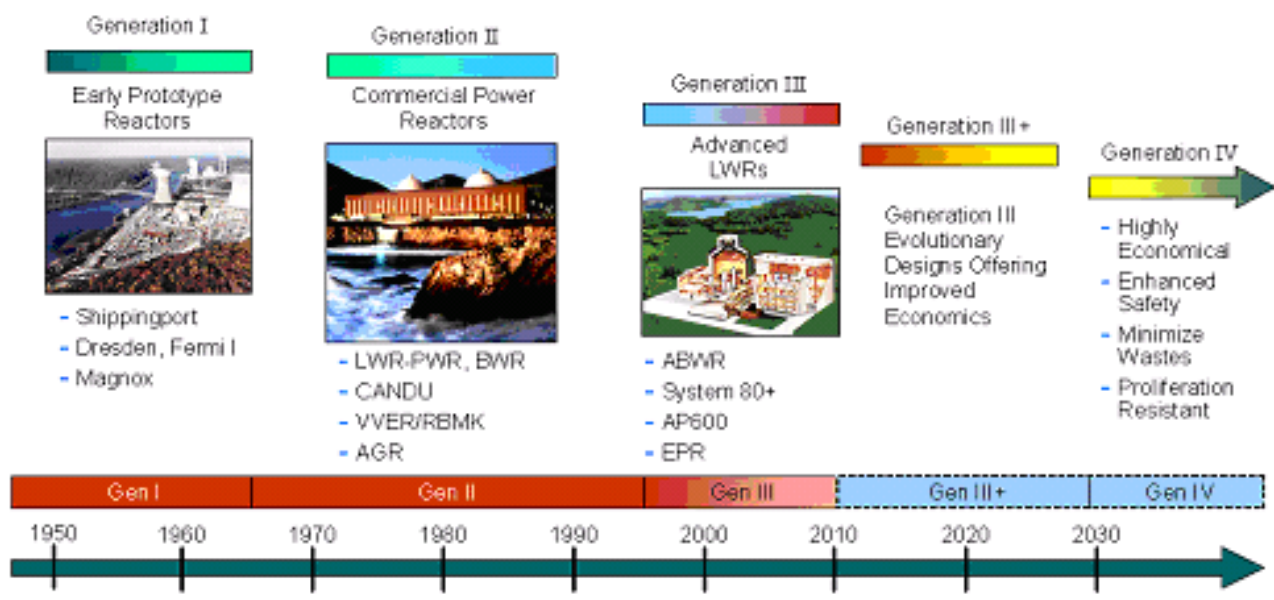

Gambar 1. Evolusi Teknologi Reaktor Daya Nuklir (PLTN)

\section{STUDI KASUS SECARA LEBIH SPESIFIK}

\section{Perancangan Reaktor Nuklir Moduler Berumur Panjang Tanpa Pengisian Ulang Bahan Bakar}

Penelitian ini bertujuan untuk mendesain berbagai reaktor nuklir masa depan yang sesuai dengan lingkungan alam dan kebutuhan masyarakat Indonesia, dengan fokus utama reaktor moduler. Penelitian tentang ini didukung dengan penelitian-penelitian yang telah kami lakukan sebelumnya.

Tentang reaktor moduler ini ada beberapa aspek penting yang diharapkan dapat ditunjukkan sebagai hasil penelitian ini:

1. Reaktor moduler akan menghasilkan performansi keamanan yang lebih baik dengan safety margin terhadap kecelakaan yang lebih besar

2. Reaktor moduler yang optimal akan ekonomis dan dapat bersaing dengan reaktor besar

3. Sejumlah reaktor moduler dapat memenuhi keseluruhan kriteria reaktor generasi IV : inherent safety, memanfaatkan cadangan U-238, dapat membakar limbah, dan tak mudah disalahgunakan untuk kepentingan lain.

4. Reaktor moduler akan membantu mengatasi krisis energi listrik di Indonesia khususnya di luar Jawa

Hasil riset ini menghasilkan disain-disain optimal reaktor moduler dari beberapa tipe LMFBR, LWR, HTGR, dan ADS. Selain itu juga akan dihasilkan disain rujukan untuk pemilihan dan pengembangan reaktor nuklir kecil yang dapat diterapkan di luar Jawa atau dalam konteks moduler menghasilkan daya besar 
untuk daerah pulau Jawa. Data-data ini meliputi data disain dan performansi keselamatannya. Juga akan dihasilkan rekomendasi tentang skenario penerapan energi nuklir berdasarkan optimasi di atas. Secara lebih rinci dari penelitian ini dihasilkan:

1. Hasil optimal perhitungan disain dan analisis keselamatan beberapa tipe reaktor moduler untuk aplikasi di Indonesia meliputi LMFBR berpendingin Pb-Bi atau Pb, LWR inovatif, dan HTGR

2. Sistem analisis simulasi untuk disain reaktor ADS dan reaktor untuk kegunaan khusus

3. Disain ADS dengan melibatkan analisis statik dan analisis kecelakaannya

4. Rancangan beberapa skenario terbaik implementasi energi nuklir di Indonesia

Dalam optimasi disain reaktor berpendingin $\mathrm{Pb}-\mathrm{Bi}$ berukuran kecil yang dapat dioperasikan dalam waktu lama tanpa pengisian ulang bahan bakar, telah ditempuh optimasi core yang berumur lama dengan mengadopsi konsep penempatan bahan fertil U-238 di tengah teras untuk menjaga agar rasio konversi internal teras relatif konstan. Dengan demikian dapat diperoleh ekses reaktivitas yang kecil selama operasi reaktor. Selanjutnya reflektor dibuat tak terlalu tebal; dan bila perlu diberi bahan absorber untuk memaksimalkan koefisien densitas pendingin. Dengan kombinasi ini dan penggunaan bahan bakar jenis nitrida maka dapat diharapkan sistem dengan internal feedback yang memungkinkan kemampuan inherent safety.

Contoh hasil perhitungan adalah sebagaimana ditunjukkan dalam Gambar 2 serta dalam Tabel 3. Gambar 2 menunjukkan konfigurasi teras untuk desain SPINNOR (Small Pb-Bi Cooled No-On-site refueling Nuclear Reactor) dan VSPINNOR (Very Small Pb-Bi Cooled No-On-site refueling Nuclear Reactor), yang merupakan hasil optimasi dalam riset ini.

\begin{tabular}{|c|l|l|l|l|l|}
\hline $\mathrm{S}$ & $\mathrm{S}$ & $\mathrm{S}$ & $\mathrm{S}$ & $\mathrm{S}$ & $\mathrm{S}$ \\
\hline $\mathrm{R}$ & $\mathrm{R}$ & $\mathrm{R}$ & $\mathrm{R}$ & $\mathrm{R}$ & $\mathrm{S}$ \\
$\mathrm{C} 2$ & $\mathrm{C} 2$ & $\mathrm{C} 2$ & $\mathrm{C} 2$ & $\mathrm{R}$ & $\mathrm{S}$ \\
\hline $\mathrm{C} 1$ & $\mathrm{C} 1$ & $\mathrm{C} 1$ & $\mathrm{C} 2$ & $\mathrm{R}$ & $\mathrm{S}$ \\
\hline $\begin{array}{c}b \\
\mathrm{~B} 2\end{array}$ & $\mathrm{~B} 2$ & $\mathrm{C} 1$ & $\mathrm{C} 2$ & $\mathrm{R}$ & $\mathrm{S}$ \\
\hline $\begin{array}{c}b \\
\mathrm{~B} 1\end{array}$ & $\mathrm{~B} 2$ & $\mathrm{C} 1$ & $\mathrm{C} 2$ & $\mathrm{R}$ & $\mathrm{S}$ \\
\hline
\end{tabular}

Gambar 2. Konfigurasi Teras Dari Reaktor Kecil SPINNOR/VSPINNOR 
Gambar 3 menunjukkan deskripsi umum sistem utama reaktor SPINNOR dan VSPINNOR. Tampak bahwa pembangkit uap (Steam generator-SG) diletakkan di dalam pressure vessel dan digunakan konfigurasi sistem tanki (pool type fast reactors).

Tabel 3 menunjukkan parameter utama dari SPINNOR dan VSPINNOR. Tampak bahwa untuk SPINNOR A umur operasinya adalah 15 tahun tanpa pengisian ulang bahan bakar untuk daya 55 MWth atau 20 MWe. SPINNOR B dapat dioperasikan dalam 25 tahun dengan daya 27.5 MWth atau 10 MWe. VSPINNOR dapat dioperasikan dalam 35 tahun tanpa pengisian ulang bahan bakar untuk daya 17.5 MWth atau 6.25 MWe. Perlu ditambahkan di sini bahwa plutonium yang digunakan di sini berasal dari hasil produksi di PWR setelah dibiarkan meluruh selama 25 tahun. Ini dilakukan untuk mengurangi jumlah kandungan Pu-241 yang akan meluruh menjadi Am-241. Pada fluks netron agak rendah seperti pada disain reaktor kecil maka kandungan yang tinggi dari Pu-241 dapat menjadi masalah karena proses meluruhnya ke Am-241 dapat menyebabkan hilangnya reaktivitas secara signifikan.

Tabel 3. Spesifikasi dari Disain SPINNOR dan VSPINNOR

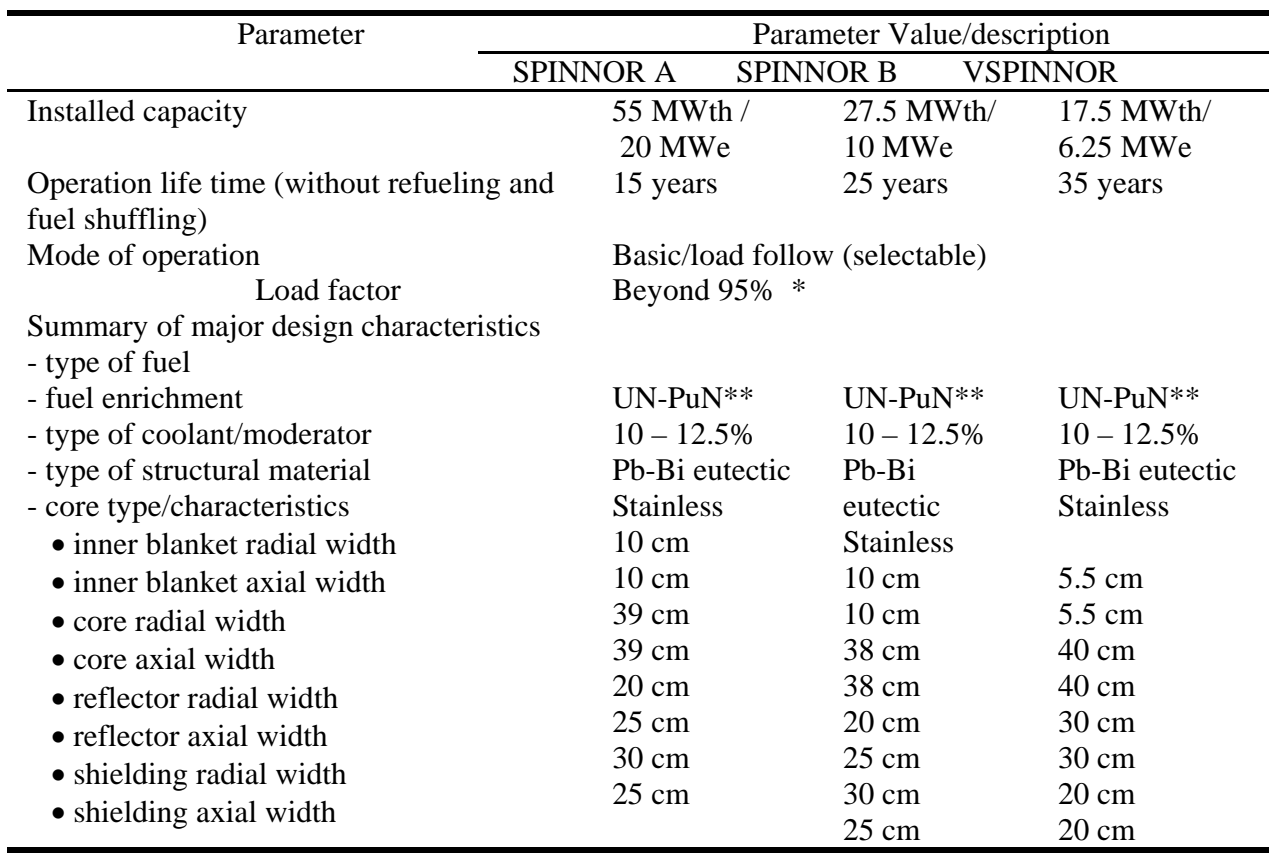

* The load factor is boasted easy maintenance due to no refueling or fuel shuffling required during their operation.

** We used plutonium from PWR after 25 years of cooling down.

Tabel 3 berisi sejumlah parameter netronik penting untuk SPINNOR dan VSPINNOR yang meliputi fraksi netron tunda, konstanta balikan reaktivitas, reaktivitas void, dan ekses reaktivitas sepanjang proses burn up. 


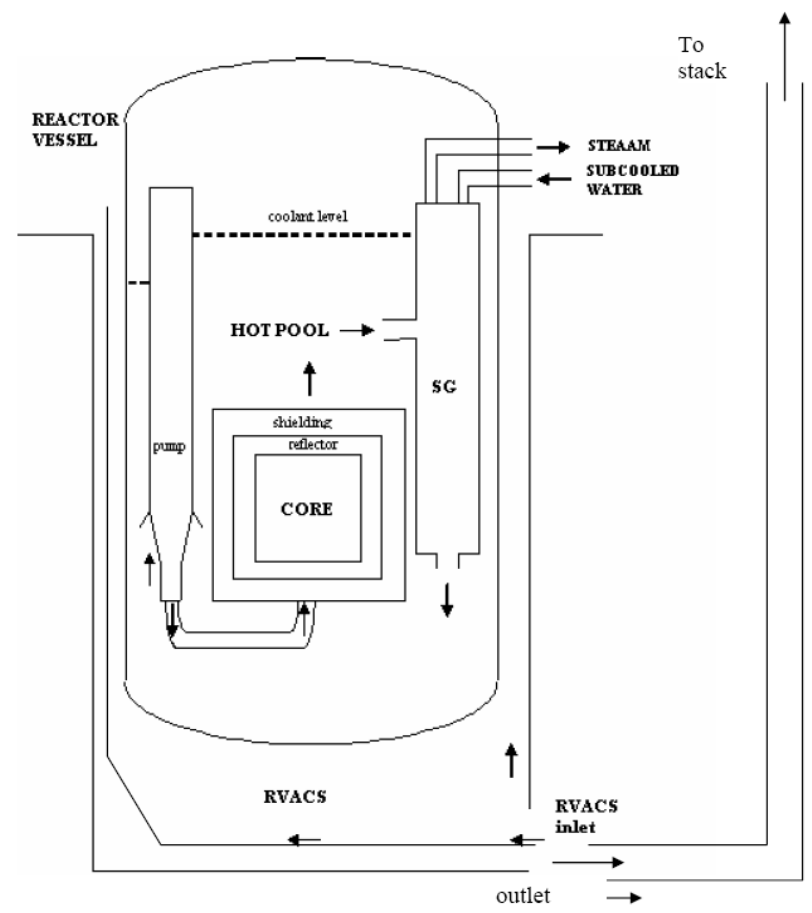

Gambar 3. Deskripsi Umum Disain SPINNOR AND VSPINNOR

Tampak bahwa tanpa proteksi pematian reaktor maka reaktor ini dapat bertahan terhadap kecelakaan hilangnya daya pompa secara total dengan mengalami kenaikan temperatur di pendingin, kelongsong (cladding) dan bahan bakar yang selanjutnya menyebabkan balikan reaktivitas negatif yang akan menekan daya untuk turun ke level yang dapat ditangani dengan sirkulasi alamiah.

Untuk meningkatkan kemampuan inherent safety terhadap kecelakaan yang diinisiasikan oleh hilangnya daya pompa maka daya sirkulasi alamiah ditingkatkan dengan memperbesar pitch dan diameter bahan bakar dan dengan menambahkan chimney. Dengan demikian sirkulasi diperoleh minimal 30 \% dari daya penuh dan jauh lebih besar untuk ukuran daya yang kecil (SPINNOR B dan VSPINNOR) dan ini sangat berguna agar sistem dapat bertahan secara internal terhadap kecelakaan hipotetis. Selain itu juga tengah dilakukan optimasi untuk reaktor berbahan bakar jenis oksida uranium dan oksida plutonium.

Selain reaktor berpendingin $\mathrm{Pb}-\mathrm{Bi}$, juga dilakukan studi disain dan optimasi reaktor daya kecil moduler berpendingin air yang dapat dioperasikan untuk waktu 10-15 tahun tanpa pengisian ulang bahan bakar. Di sini digunakan siklus bahan bakar Thorium dengan pertimbangan bahwa untuk spektrum termal convertion ratio dari siklus bahan bakar Thorium jauh lebih baik dari pada siklus bahan bakar uranium-plutonium. Dengan demikian penggunaan siklus bahan 
bakar thorium diharapkan memungkinkan dirancangnya reaktor daya moduler berpendingin air yang dapat dioperasikan dalam waktu lama tanpa perlu adanya ekses reaktivitas yang sangat besar di awal siklus seperti yang lazim terjadi pada reaktor daya berpendingin air konvensional (PWR, BWR).

Hasil-hasil penelitian di tahun pertama ini menunjukkan kecenderungan ini. Di sini telah berhasil dirancang reaktor daya moduler berpendingin air dengan ekses reaktivitas antara $1 \sim 2 \%$ untuk waktu operasi 10 tahun. Sebagai perbandingan reaktor PWR dan BWR konvensional memerlukan ekses reaktivitas sampai sekitar 30\% di awal siklus untuk jangka operasi 1 tahun.

Selain itu pada tahun pertama ini telah pula dilakukan studi tentang reaktor air didih dengan siklus panjang. Strategi yang dilakukan adalah dengan memanfaatkan peluang menurunkan moderasi netron pada BWR dengan cara mengatur faktor kualitas campuran uap-air pada pendingin reaktor BWR tersebut. Dengan spektrum yang lebih cepat maka terjadi peningkatan rasio koversi bahan bakar sehingga umur reaktor dapat diperpanjang dengan ekses reaktivitas awal yang masih lebih kecil dari BWR kovensional. Di sini dihitung 3 ukuran daya reaktor : 150, 300, dan 450 MWth.

\section{Perancangan Reaktor Daya Nuklir yang Dioperasikan di Atas Kapal}

Dalam penelitian ini para mahasiswa diajak mengembangkan sistem analisis untuk menangani perancangan reaktor daya yang dapat dioperasikan di atas kapal. Suatu modifikasi penting harus dilakukan pada analisis termal hidroliknya dibandingkan dengan kasus reaktor yang dioperasikan di darat. Selain itu juga dilakukan optimasi disain baik dalam aspek netronik, termal hidrolik maupun aspek keselamatannya. Contoh-contoh hasil simulasinya dapat dilihat pada Gambar 4 dan 5.

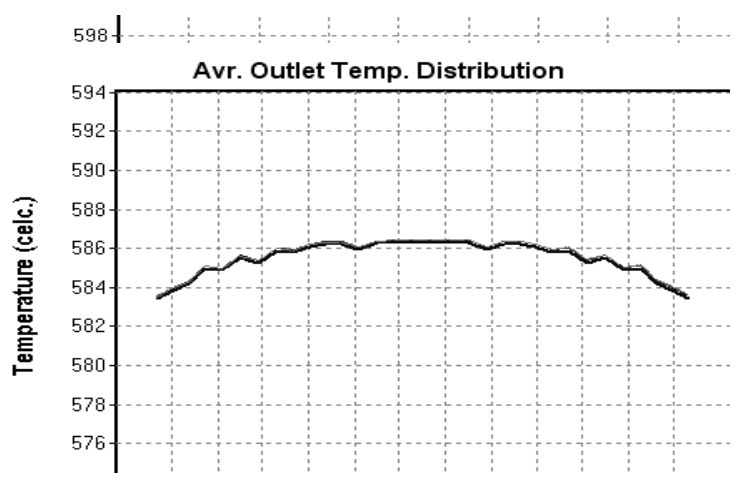

Gambar 4. Perubahan Distribusi Temperatur Keluaran Sebagai Fungsi Sudut Elevasi Untuk Teras Pipih (Pancake) 


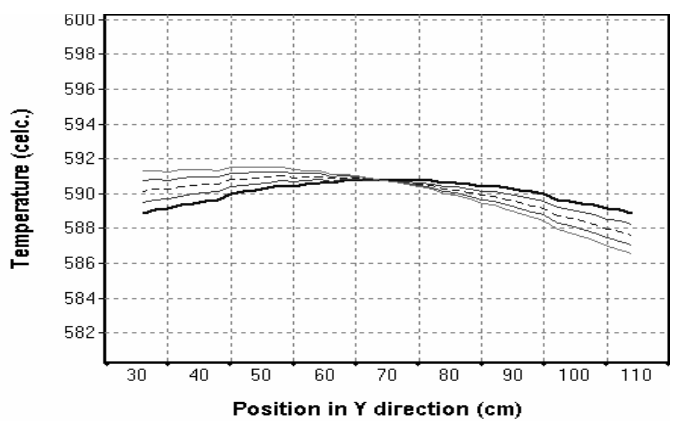

Gambar 5. Perubahan Distribusi Temperatur Keluaran Sebagai Fungsi Sudut Elevasi Untuk Teras Setimbang (Balance)

Gambar 4 dan 5 menunjukkan perubahan distribusi temperatur keluaran pendingin di teras untuk perubahan sudut elevasi. Tampak bahwa perubahan sudut elevasi menyebabkan redistribusi aliran sehingga menyebabkan perubahan suhu keluaran. Juga tampak bahwa karakteristik geometri teras juga berpengaruh pada perubahan distribusi aliran teras.

Penelitian dalam Bidang Data Nuklir, Siklus Bahan Bakar, dan Spektroskopi

Di bidang-bidang ini cukup banyak mahasiswa yang dilibatkan dalam pengembangan kemampuan dalam menguasai Iptek terkait dengan data Nuklir baik menyangkut modifikasi pustaka data Nuklir untuk perhitungan homogenisasi sel bahan bakar, maupun perhitungan-perhitungan yang lebih mendasar termasuk aspek komputasinya.

Menyangkut siklus bahan bakar dikembangkan analisis siklus bahan bakar dan optimasi penanganan limbah Nuklir baik menyangkut reaktor PWR dan BWR yang saat ini banyak digunakan, maupun untuk reaktor-reaktor lanjut generasi IV. Hasil-hasil penelitian mahasiswa sangat baik dan banyak dipublikasikan dalam seminar dan jurnal ilmiah.

Menyangkut aspek instrumentasi dalam bidang Nuklir cukup banyak mahasiswa yang berminat dan dilibatkan dalam pengembangan sistem spektroskopi dengan berbagai bentuk aplikasinya.

\section{KESIMPULAN}

Pelibatan mahasiswa dalam kegiatan riset merupakan salah satu strategi yang dapat ditempuh untuk menciptakan SDM handal dan berkualitas dalam bidang Nuklir khususnya yang menuntut kemampuan analisis yang cukup tinggi, baik dalam bidang perancangan netronik, perancangan termal hidrolik dan analisis keselamatan reaktor.

Berdasarkan pengalaman yang telah cukup lama (10 tahun lebih) mahasiswa S1-S2 maupun S3 dapat mengikuti kegiatan riset dalam bidang 
reaktor Nuklir asalkan sebelumnya ditunjang dengan perkuliahan dan praktikum yang memadai sehingga mereka memiliki kesiapan yang baik.

Riset dalam disain-disain reaktor Nuklir mutakhir tak berarti bahwa mahasiswa tak mampu menangani reaktor konvensional. Mereka yang menangani reaktor termal berbasis LWR inovatif dengan cukup mudah mampu melakukan perhitungan dengan disain LWR konvensional.

\section{DAFTAR PUSTAKA}

1. ZAKI S., and SEKIMOTO, H., 1995, "Safety Aspect of Long Life Small Safe Power Reactors”, Analysis of Nuclear Energy.

2. ZAKI S. and SEKIMOTO, H., 1995, "Design and Safety Aspect of Lead and Lead Bismuth Cooled Long-Life Small-safe Fast Reactor for Various Core Configuration”, Journal of Nuclear Science and Technology 32/9.

3. ZAKI S. and SEKIMOTO, H., 1996, “Accident Analysis of lead or lead-bismuth Cooled Small Safe Long-life Fast Reactor Using Metallic or Nitride Fuel”, Nuclear Eng. And Design, 162(1996), p. 205-222.

4. EPUNG S.B., ZAKI S., A. WARIS, and BAMBANG A.W., 2005 "Reactor Core Design Optimization of The 200 MWth Pb-Bi Cooled Fast Reactors for Hydrogen Production”, Asian Physics Seminar December 7-8-2005, Grand Aquila Hotel, Bandung, Indonesia.

5. ZAKI SU’UD et al., 2005, "Development of WEB based Reactor Analysis System”, Asian Physics December 7-8-2005, Grand Aquila Hotel, Bandung, Indonesia.

6. MUH. NURUL SUBKHI and ZAKI SU'UD, 2005, "Preliminary Study of Small Long-Life PWR Core with Thorium Protactinium Fuelled”, Asian Physics December 7-8-2005, Grand Aquila Hotel, Bandung, Indonesia.

7. DIAN FITRIYANI and ZAKI S., ”Design Study of Ship Based Nuclear Power Reactors: Safety Analysis with Quasistatic Approach”, Asian Physics December 7-8-2005, Grand Aquila Hotel, Bandung, Indonesia.

8. EKA S and ZAKI S., 2005, ”Design Study of Thorium Cycle Based Tight Lattice Long Life BWR”, Proceeding of GLOBAL October 9-13 2005 Conference, Tsukuba.

9. TOPAN S, S.M. NURUL, Y. ASTUTI and ZAKI S., 2005, "Neutronic Design Study of Small Long Life PWR with (Th,U) $\mathrm{O}_{2}$ fuel”, Proceeding of GLOBAL October 9-13 2005 Conference, Tsukuba

10. ZAKI SU'UD, 2005, ”Design Study of Small Pb-Bi Cooled Non-Refueling Nuclear Power Reactors (SPINNOR)”, Proceeding of GLOBAL October 9-13 2005 Conference, Tsukuba.

11. ZAKI SU'UD, BAKRIE ARBIE, and SEDYARTOMO S., 2005, “The Prospect of MOX Fuel Based Pb-Bi Cooled Small Nuclear Power Reactors', Progress of Nuclear Energy, Vol. 47, h.212-221. 